(2) Open Access Full Text Article

REVIEW

\title{
Immune checkpoint blockade: the role of PD-I- PD-L axis in lymphoid malignancies
}

This article was published in the following Dove Press journal:

OncoTargets and Therapy

28 April 2017

Number of times this article has been viewed

\section{Cristina Ilcus' \\ Cristina Bagacean ${ }^{1,2}$ \\ Adrian Tempescul ${ }^{3}$ \\ Cristian Popescu' \\ Andrada Parvu ${ }^{1,4}$ \\ Mihai Cenariu ${ }^{5}$ \\ Corina Bocsan ${ }^{6, *}$ \\ Mihnea Zdrenghea ${ }^{1,4, *}$ \\ 'Department of Hematology, Iuliu Hatieganu University of Medicine and Pharmacy, Cluj- Napoca, Romania; 'Laboratory of Immunology and Immunotherapy, Brest University Medical School, CHRU Morvan, ${ }^{3}$ Department of Clinical Hematology, Institute of Cancerology and Hematology, Brest, France; ${ }^{4}$ Department of Hematology, Ion Chiricuta Oncology Institute, ${ }^{5}$ Biotechnology Research Center, University of Agricultural Sciences and Veterinary Medicine, ${ }^{6}$ Department of Clinical Pharmacology, Iuliu Hatieganu University of Medicine and Pharmacy, Cluj-Napoca, Romania \\ *These authors contributed equally to this work}

Correspondence: Mihnea Zdrenghea Department of Hematology, luliu Hatieganu University of Medicine and Pharmacy, Ion Chiricuta Oncology Institute, 73, 2 I Decembrie Blvd., 400 I 24 Cluj-Napoca, Romania

Tel +4074 II 10480

$\mathrm{Fax}+40264598606$

Email mzdrenghea@umfcluj.ro
Abstract: The co-inhibitory receptor programmed cell death (PD)-1, expressed by immune effector cells, is credited with a protective role for normal tissue during immune responses, by limiting the extent of effector activation. Its presently known ligands, programmed death ligands (PD-Ls) 1 and 2, are expressed by a variety of cells including cancer cells, suggesting a role for these molecules as an immune evasion mechanism. Blocking of the PD-1-PD-L signaling axis has recently been shown to be effective and was clinically approved in relapsed/refractory tumors such as malignant melanoma and lung cancer, but also classical Hodgkin's lymphoma. A plethora of trials exploring PD-1 blockade in cancer are ongoing. Here, we review the role of PD-1 signaling in lymphoid malignancies, and the latest results of trials investigating PD-1 or PD-L1 blocking agents in this group of diseases. Early phase studies proved very promising, leading to the clinical approval of a PD-1 blocking agent in Hodgkin's lymphoma, and Phase III clinical studies are either planned or ongoing in most lymphoid malignancies.

Keywords: immune checkpoint blockade, programmed cell death 1, b7 antigens, hematological cancer, lymphoma, chronic lymphocytic leukemia

\section{Background}

Regulation of T-cell activation consists of two distinct signals. The primary signal is represented by a specific interaction between the T-cell receptor (TCR) and the antigen bound by the major histocompatibility complex molecule on the surface of the antigen presenting cells (APCs). The second signal is mediated through co-stimulation of lymphocyte receptor CD28 by B7 ligands (CD80, CD86) induced on the APC by pathogens, playing an important role in T-cell activation and tolerance. However, co-inhibitory signaling can limit activation and suppress effector T-cell actions and is as such credited with a protective role, by limiting immune damage to healthy tissue and inducing tolerance. Molecules such as cytotoxic T lymphocyte associated protein 4 (CTLA-4), programmed cell death 1 (PD-1) and its ligands, programmed death-ligand (PD-L) 1 and 2, are members of the B7/CD28 ligand-receptor family and represent the most investigated inhibitory immune checkpoints at present. ${ }^{1}$

The PD-1 (CD279) receptor is a transmembrane protein of the immunoglobulin superfamily and was first identified and characterized in 1992 in mice. ${ }^{2,3}$ It is a co-inhibitory receptor found on the surface of T cells, B cells, monocytes, and activated natural killer cells. ${ }^{4}$ The receptor interacts with its two ligands, PD-L1 (B7-H1, CD274) and PD-L2 (B7-DC, CD273) 5,6 expressed by APCs, PD-L1 being regarded as the main mediator of PD-1 dependent immunosuppression. ${ }^{7}$ This ligand is constitutively expressed on T cells, B cells, macrophages, and dendritic cells, as well as nonimmune cells, such as endothelial cells, $\beta$ pancreatic cells, glial cells, epithelial 
cells, and muscle fibers. ${ }^{8-10}$ In contrast to PD-L1, PD-L2 has a more narrow expression profile, restricted to APC and helper T cells, but an affinity approximately two to sixfold higher, hence the possibility of competition between ligands for the binding of the receptor. ${ }^{5,11,12}$ Also, the mechanism of action of the two ligands differs: PD-L1 binds to both PD-1 and CD80, whereas PD-L2 interacts directly with PD-1. ${ }^{6}$

The PD-1-PD-L pathway downregulates the immune response to maintain a balance between $\mathrm{T}$ cell activation and healthy tissue destruction, thus preserving peripheral tolerance (Figure 1). ${ }^{13-15} \mathrm{~T}$ cell activation is followed by upregulation of PD-1 and production of cytokines, such as interferon (IFN)- $\gamma$ and interleukin (IL)-4. These cytokines upregulate PD-L1 expression through a positive feedback mechanism, having a role in preventing autoimmunity and tissue destruction. ${ }^{16,17}$ In case of an inadequate immune response, prolonged antigen stimulation causes PD-1 upregulation and $\mathrm{T}$ cell exhaustion. The critical role of downregulation of the immune system through PD-1 stimulation has been demonstrated in a series of studies on chronic viral infections such as HIV, hepatitis B and hepatitis C, whereas $\mathrm{CD}^{+} \mathrm{T}$ cells have impaired proliferation responses and cytokine production, and are often described as exhausted T cells. ${ }^{18-20}$ In these cases there is a persistent $\mathrm{T}$ cell activation with PD-1 upregulation and, consecutively, PD-1-PD-L1 pathway stimulation, resulting in inactive $\mathrm{T}$ cells, infection persistence and a minimized immune aggressive effect on healthy tissues. ${ }^{21}$

\section{Role of PD-I-PD-L pathway in cancer}

Involvement of the PD-1-PD-L pathway in cancer has been demonstrated in a broad variety of solid malignancies, such as breast cancer, colon carcinoma, lung cancer, renal cell cancer, melanoma, ovarian cancer, bladder cancer, pancreatic cancer, and various hematologic malignancies. ${ }^{7,22-26}$ PD-1 levels are considerably upregulated on tumor-infiltrating lymphocytes (TILs) in comparison to peripheral blood or healthy tissues infiltrating $\mathrm{T}$ cells, and consecutively TILs exert an impaired antitumor activity. ${ }^{5,27-30}$ Compared to PD-1lymphocytes, PD-1+ TILs exhibit an "exhausted" phenotype, through decreased TCR signaling, defective calcium flux and diminished cytokine production including IL-2, IFN- $\gamma$, and TNFo. ${ }^{28,29,31-34}$ PD-L1 expression is encountered in a large variety of tumors as well: lung, breast, colon, skin, ovarian,

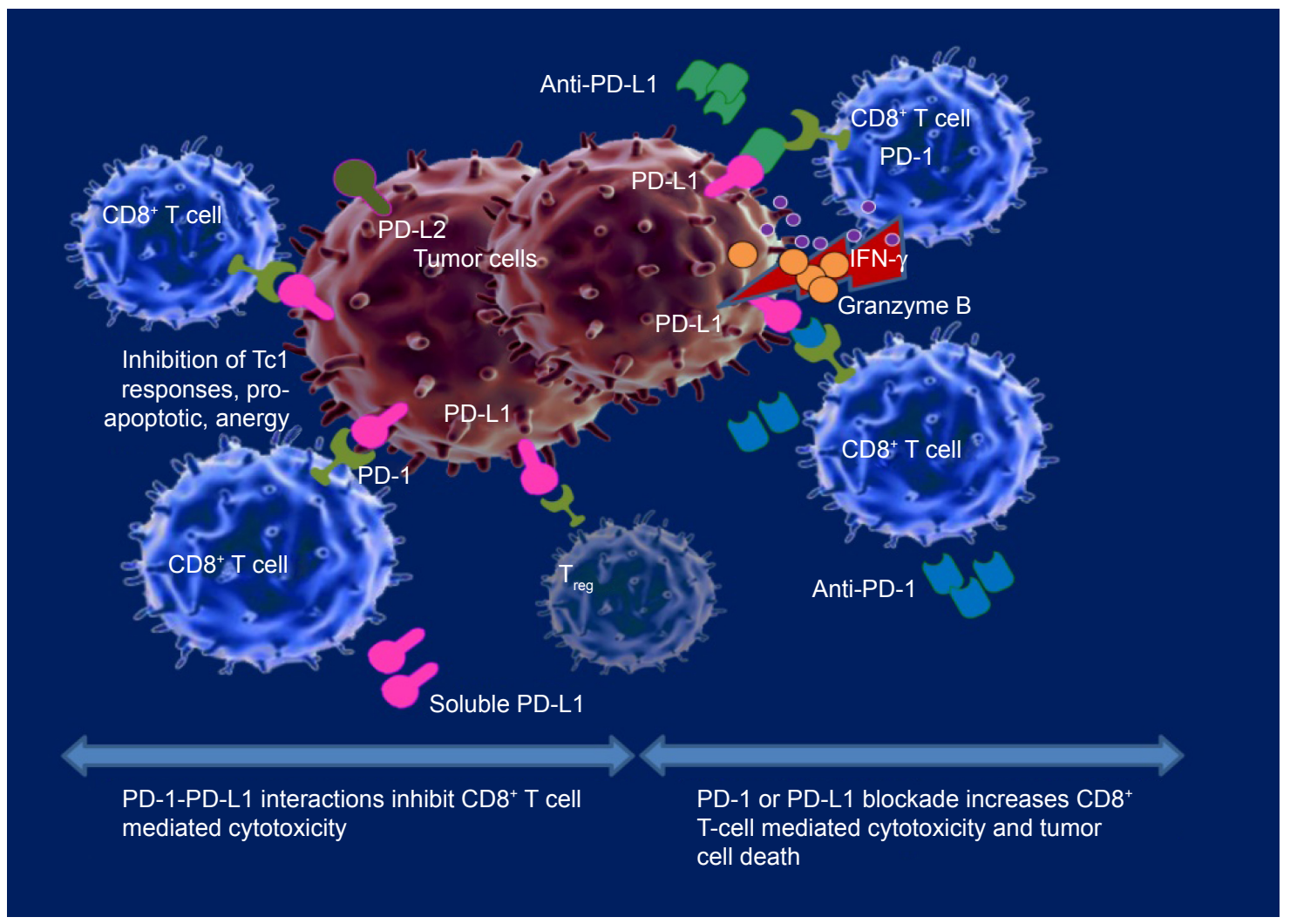

Figure I PD-I- PD-LI axis blockade in cancer.

Notes: Signaling through PD-I induces T cell anergy, with the physiological role of protecting from autoimmune damage. This mechanism is exploited by tumor cells expressing PD-I ligands to escape immunity by suppressing host antitumor T cell responses (left). PD-I or PD-LI blocking antibodies have the capability to restore cytotoxic T cell functions including IFN-y and perforin production, which can lead to impressive antitumor responses (right).

Abbreviations: PD, programmed cell death; PD-LI, programmed cell death receptor ligand-I. 
gastric, pancreatic cancers, and different types of hematologic malignancies. ${ }^{17,35-38}$ The ligand is upregulated at the surface of cancer cells, intratumoral macrophages and APCs from the surrounding tumor microenvironment. PD-L1 appears to act as an antiapoptotic factor in cancer cells, as its expression is strongly associated with in vivo tumorigenesis and invasion, and in vitro resistance to $\mathrm{T}$ cell mediated lysis. ${ }^{1,39}$ The ligand upregulation is triggered by proinflammatory cytokines such as IFN- $\gamma$ produced by lymphocytes present in the tumor microenvironment. ${ }^{38}$ Therefore, activation of the PD-1PD-L1 immune checkpoint pathway in cancer represents an adaptive mechanism of resistance used by cancer cells against TILs, suggesting the presence, yet exhaustion of an antitumor T-cell immune response.

In vitro studies have demonstrated that blockade of PD-1 or PD-L1 using monoclonal antibodies restored T cell cytotoxic capacity and IFN- $\gamma$ production (Figure 1). ${ }^{1,40}$ Subsequently, clinical studies have confirmed these findings, with PD-1 and PD-L1 blocking antibodies being successful at present and having been recently approved by the US Food and Drug Administration for the treatment of metastatic melanoma, nonsmall cell lung cancer, renal cell and urothelial carcinoma, head and neck cancer, and classical Hodgkin's lymphoma (cHL) (Table 1).

\section{Potential biomarkers for the efficacy of PD-I-PD-L blockade}

PD-L1 and/or PD-1 expression were actively investigated as potential biomarkers to predict the efficacy of PD-1-PD-L1 axis blockade. Initial studies and preclinical data in solid tumors have found a correlation between PD-L1 expression and clinical benefits of PD-1 blockade, suggesting that the ligand might be a promising biomarker, with a better association to the treatment response in comparison with PD-1 expression. ${ }^{41}$ A strong correlation between PD-L1 ${ }^{+}$ expression in malignant cells and the response to PD-1 blockers has been demonstrated in lung cancer, ${ }^{42}$ but also in melanoma, ${ }^{43}$ breast cancer, ${ }^{44}$ hepatocellular carcinoma, ${ }^{45}$ and colorectal cancer ${ }^{46}$ whereas in renal cell carcinoma and urothelial carcinoma PD-L1 ${ }^{+}$infiltrating cells correlate best with response to anti-PD-L1 antibodies. ${ }^{47-49}$

Some of the difficulties encountered in PD-L1 evaluation were the limited tumoral tissue availability, the tissue heterogeneity, and the markers' dynamic, the expression of which is influenced by infections, malignancies, and treatment. Although early phase studies in advanced solid cancers such as melanoma, lung cancer, colorectal cancer, renal-cell cancer, and prostate cancer demonstrated clinical benefits in PD-L1 ${ }^{+}$ tumors and none in PD-L1 ${ }^{-}$cohorts, ${ }^{1,7,50}$ a recent Phase III randomized trial of nivolumab, an anti-PD-1 human IgG4 monoclonal antibody, in melanoma showed improved survival in all subgroups, regardless of the levels of PD-L1 expression, but objective response rates (ORRs) were significantly higher in the PD-L1 ${ }^{+}$subgroup (52.7\%) than in the PD-L1- one $(33.1 \%){ }^{51}$ Nevertheless, even patients with tumors lacking PD-L1 expression can benefit from anti-PD-1 therapy, probably due to tumor microenvironment responsiveness. ${ }^{1,49,52}$ Therefore, a lack of PD-L1 expression is not an appropriate biomarker for patient exclusion, with PD-L1 status being rather appropriate for stratification into groups that would benefit from anti-PD-1 monotherapy and groups that are in need of combination therapy in order to achieve a better response..$^{52}$ However, the recent approval by the US Food and Drug Administration (FDA) of anti PD-1 agent pembrolizumab for nonsmall cell lung cancer is conditional on the demonstration of tumor PD-L1 expression by an FDA-approved test.

The differences between data obtained in various clinical trials may be attributed to different cutoff values for PD-L1 expression varying in different trials from as low as $1 \%{ }^{53}$ to the more frequently used $5 \%,{ }^{54,55}$ and even as high as $50 \%$ of tumor cells. ${ }^{53}$ Uniformization and standardization of PD-L1 expression assessment, including the positive cutoff value,

Table I US Food and Drug Administration-approved PD-I checkpoint blockers

\begin{tabular}{|c|c|c|c|}
\hline Drug & Activity & Approved for & Observations \\
\hline \multirow[t]{4}{*}{ Nivolumab } & Anti-PD-I human lgG4 mAb & Metastatic melanoma & Single or in combination with ipilimumab \\
\hline & & Classical Hodgkin's lymphoma & After ASCT and brentuximab vedotin failure \\
\hline & & Nonsmall cell lung cancer & Progression after platinum and/or other agents \\
\hline & & Renal cell carcinoma & After prior anti-angiogenic therapy \\
\hline \multirow[t]{3}{*}{ Pembrolizumab } & Anti-PD-I humanized lgGI mAb & Melanoma (unresectable/metastatic) & \\
\hline & & Nonsmall cell lung cancer & Approval restricted to PD-LI expressing tumors \\
\hline & & $\begin{array}{l}\text { Head and neck squamous cell } \\
\text { carcinoma }\end{array}$ & $\begin{array}{l}\text { Progression after or on platinum-containing } \\
\text { treatment }\end{array}$ \\
\hline \multirow[t]{2}{*}{ Atezolizumab } & Anti-PD-LI humanized IgGI mAb & Metastatic nonsmall cell lung cancer & Progression after platinum and/or other agents \\
\hline & & Urothelial cancer & Metastatic or locally advanced \\
\hline
\end{tabular}

Abbreviations: ASCT, autologous stem cell transplantation; PD-I, programmed cell death receptor I; PD-LI, programmed cell death receptor ligand I. 
the selective staining of tumor cells or infiltrating immune cells and the types of antibody used, is of major significance for future trials. A sensitivity analysis of 20 trials of PD-1 axis blockers' efficacy according to PD-L1 expression in solid tumors which used thresholds of $1 \%$ and $5 \%$ ligand expression by immunostaining, underscored the above shortcomings and concluded that a cutoff of 5\% should be used for PD-L1 expression assessment. ${ }^{56}$

The mechanism of anti-PD-1 therapy action differs between solid tumors and hematologic malignancies. PD-1 evaluation as a prognostic marker in lymphoid malignancies has yielded variable results. While in Hodgkin's lymphoma, PD-1 expression correlated with overall survival (OS) being a stage-independent negative prognostic factor, ${ }^{57,58}$ the same receptor expressed by TILs represents a positive prognostic marker for progression-free survival (PFS) and OS in cases of follicular lymphomas. ${ }^{59}$

Besides surface expression of PD-1 and its ligands, other biomarkers have been evaluated to predict efficacy of the PD-1 signaling blockade. These include the presence of soluble PD-L1 (sPD-L1) in patients' sera, ${ }^{60,61}$ the ratio of immune cells subtypes in the tumor microenvironment, ${ }^{62,63}$ and immune gene expression signature. ${ }^{64}$ Specific biomarkers of PD-1 axis blockade investigated in lymphoproliferative disease will be discussed in the respective sections below.

\section{PD-I-PD-LI pathway blockade in hematological malignancies}

Hematological cancers have, too, developed diverse strategies of evading the immune system. Since the impressive effect of PD-1 blockade has been proven, PD-1 or PD-L1 targeted antibodies are being investigated for the treatment of various types of hematological malignancies. The use of immune checkpoint blockade in these pathologies is limited, but has shown clinical benefit in relapsed or refractory disease settings. ${ }^{3}$ Markers of the PD-1 pathway, evaluated by immunohistochemistry or flow cytometry, have been confirmed in hematologic diseases such as multiple myeloma (MM), acute myeloid leukemia, and Hodgkin and non-Hodgkin lymphomas (NHL). ${ }^{57,65}$ Of the NHLs, PD-1 and ligands expression has been confirmed in chronic lymphocytic leukemia (CLL), ${ }^{66}$ follicular lymphoma (FL), diffuse large B-cell lymphoma (DLBCL), primary mediastinal large B-cell lymphoma (PMBL), anaplastic large-cell lymphoma, and angioimmunoblastic T-cell lymphoma (AITL). ${ }^{57,67-69}$

The timing of PD-1 blockade initiation is crucial and there are several temporal aspects under consideration in the optimization of treatment outcome. First, initiation of anti-PD-1 antibody treatment prior to chemotherapy may enhance antitumor immune responses offering a better support for subsequent treatment. Second, use of immune checkpoint blockade concomitantly with classical chemotherapy could enhance the antitumor response by creating a tumor antigenrich environment consecutive to cell lysis, which can further stimulate the immune system. Finally, a third option would be the administration of PD-1 blockers after the cytotoxic treatment, boosting the antitumor response during a period of immune reconstitution subsequent to chemotherapy-induced myelosuppression. ${ }^{57}$ Also, chemotherapy induces PD-1 expression on immune cells, favoring the immune checkpoint blockade being administered postcytotoxic treatment. ${ }^{21,70,71}$ Based on this reasoning, anti-PD-1 therapy could be applied either before autologous/allogeneic stem cells transplantation (ASCT), or to target residual disease after transplantation, when PD-1 pathways may serve as a tumor survival mechanism. ${ }^{52,72,73}$

The response to $\mathrm{PD}-1$ blockade varies significantly between different types of lymphoma, due to the diverse mechanisms responsible for the expression of co-inhibitory molecules, and no definitive correlations have been yet established. PD-L1 is an inducible molecule that can be stimulated by viral infections, TILs, or genetic changes within the tumor. ${ }^{69,74}$ Also, high levels of sPD-L1 may be secreted by tumor-infiltrating cells following proinflammatory cytokine stimulation. ${ }^{36}$

While in solid tumors PD-L1 is highly expressed on cancer cells but minimally expressed in the surrounding normal tissue, ${ }^{22}$ in up to $73 \%$ of T-cell NHL subtypes PD-L1 expression is more prevalent on tumor-infiltrating cells as compared to malignant cells, contributing to immune suppression. ${ }^{75,76}$

DLBCL cells employ multiple mechanisms for the upregulation of PD-1 and its ligands, occasionally present on the same tumor cell, in contrast to FL, where PD-1 is highly expressed in the microenvironment, highlighting different immune evasion strategies. ${ }^{62,68,77,78}$

Strong PD-L1 expression in DLBCL tumor cells is significantly associated with Epstein-Barr virus (EBV) infection, and is higher in activated B cell-like than in germinal center B cell-like phenotypes. The levels of PD-1 ${ }^{+}$TIL correlated positively with the level of PD-L1 expression in tumor cells or macrophages. ${ }^{79}$

Similar to HL, where EBV latent membrane protein 1 (LMP-1) increases PD-L1 promoter activity, PD-L1 expression in DLBCL may be upregulated by EBV infection. ${ }^{80,81}$ Similar to genetic aberrations encountered in HL, several 
gene expression profiling studies demonstrated the presence of gains/amplifications of a region of chromosome 9p24 in $\sim 70 \%$ of PMBL cases, leading to a high expression of PD-L1 and 2, which distinguishes PMBL from other types of DLBCL and could serve as a molecular diagnostic tool. ${ }^{82-84}$

Primary central nervous system lymphomas (PCNSLs) and primary testicular lymphomas have also been shown to exhibit 9p24.1 copy gain and chromosomal translocation of PD-L1/PD-L2, as well as EBV-mediated upregulation of the ligands in PCNSL. ${ }^{85}$

An association between viral infections and PD-L1 expression was also observed in other lymphoid malignancies. Studies on EBV-positive natural killer/T-cell lymphoma found a high expression of PD-L1 in lymphoma

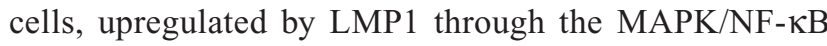
pathway. High PD-L1 expression $(>38 \%)$ and serum sPD-L1 levels $\geq 3.4 \mathrm{ng} / \mathrm{mL}$ were interpreted as independent prognostic factors for lower complete remission (CR) rates, PFS, and OS. ${ }^{86}$ Also, in extranodal NK/T-cell lymphoma (ENKTL) treated with asparaginase, high posttreatment sPD-L1 level $(>1.12 \mathrm{ng} / \mathrm{mL})$ was demonstrated to be a predictive biomarker for early relapse and poor prognosis and also a marker of minimal residual disease ${ }^{87}$ However, results from another study show that high PD-L1 expression in advanced stages of $\mathrm{EBV}^{+} \mathrm{ENKTL}$ correlates with improves $\mathrm{OS},{ }^{88}$ further studies being warranted to establish the prognostic value of PD-L1 expression in these cases. In adult T-cell leukemia/lymphoma (ATLL), HTLV-1 bZIP factor expressed by HTLV-1 infected cells upregulates PD-1 expression on both neoplastic and normal $\mathrm{CD} 4^{+} \mathrm{T}$ cells, but impedes its suppressive signals by inhibiting co-localization of PD-1 and tyrosine phosphatase (SHP-2), favoring the proliferation of infected cells and immune suppression. ${ }^{89,90}$ Both asymptomatic HTLV-1 carriers and ATLL patients express high PD-1 levels on HTLV-1-specific cytotoxic T cells, with elevated levels in patients with EBV and CMV co-infection. PD-L1 expression was only identified in ATLL cells of the patients and administration of an anti-PD-L1 or anti-PD-1 antibody stimulated $\mathrm{HTLV}^{+} \mathrm{CD}^{+} \mathrm{T}$ cell immune response. ${ }^{91,92}$

In the next sections, we review results of PD-1 blockade studies in lymphoproliferative diseases, the most relevant clinical trial efficacy reports being summarized in Table 2 .

\section{Hodgkin's lymphoma}

Hodgkin's lymphoma (HL) is an ideal candidate for anti-PD-1 therapy, because of its particular histological structure, which involves a rather small number of primary tumor-associated CD-30 ${ }^{+}$Reed Sternberg or Hodgkin cells surrounded by a granuloma-like, immune cell-rich environment. A viral or genetic-induced PD-L1 overexpression by Reed Sternberg malignant cells was also described. ${ }^{93}$ Thus, not surprisingly, of the several clinical studies evaluating PD-1 blockade efficiency in hematologic malignancies, the most promising results have been recorded for patients with cHL. Consecutively, cHL is the first hematologic malignancy in which an anti-PD-1 agent, nivolumab, has been approved, in early 2016, as salvage therapy after prior ASCT and brentuximab. The breakthrough therapy designation by the FDA is based on results of a Phase I (CheckMate-039) ${ }^{93}$ and a Phase II (Checkmate-205) ${ }^{94,95}$ trial (Table 2).

The PD-L1 gene has been identified in HL and is located on the short arm of chromosome 9p24. Amplification of genetic material in the 9p24 region is associated with PD-1 ligand overexpression in nodular sclerosis HL and also PMBL: mostly PD-L1 in HL and PD-L2 in PMBL. Amplification of this region also results in amplification of JAK2, which through JAK2-STAT signaling further stimulates PD-1 ligand overexpression. ${ }^{66,83}$ Immune cells surrounding Reed Sternberg cells include PD- $1^{+}$T-cells, whose function and IFN- $\gamma$ production can be stimulated by immune checkpoint blockade. ${ }^{38,65}$ Epstein-Barr infection, commonly associated with HL, is another mechanism involved in PD-L1 upregulation, ${ }^{80}$ viral infections being known as able to exploit the PD-1-PD-L pathway in order to induce immune tolerance. ${ }^{40,52}$

\section{Chronic lymphocytic leukemia}

CLL is the most frequent B cell malignancy, characterized by an increased proliferation and accumulation of monoclonal $\mathrm{CD}^{+} \mathrm{CD} 19^{+} \mathrm{B}$ cells in the bone marrow, lymphoid organs, and peripheral blood, promoting a tumor microenvironment which dampens the immune response and favors malignant cell proliferation and treatment resistance..$^{96,97}$ Recent studies described a functional impairment in the T-cell compartment (both $\mathrm{CD} 4^{+}$and $\mathrm{CD} 8^{+}$) reflected by alterations of their number, function and memory, as a consequence of interaction with leukemic cells. ${ }^{37,98} \mathrm{~T}$-cells are found in a state of chronic activation and have the tendency to accumulate, presenting an inversion of the normal $\mathrm{CD} 4: \mathrm{CD} 8$ ratio, higher levels of $\mathrm{CD} 8^{+} \mathrm{T}$ cells being associated with a more aggressive disease. ${ }^{99}$

The PD-1-PD-L1 axis has been shown to be involved in CLL pathogenesis. Immunohistochemistry and immunofluorescence assays of PD-1 and PD-L1 expression in lymph nodes of CLL patients demonstrated the presence of $\mathrm{PD} 1{ }^{+} \mathrm{CD} 4^{+} \mathrm{T}$ cells and PD-L $1{ }^{+} \mathrm{CD} 23^{+} \mathrm{B}$ cells. ${ }^{37}$ Both T cells 


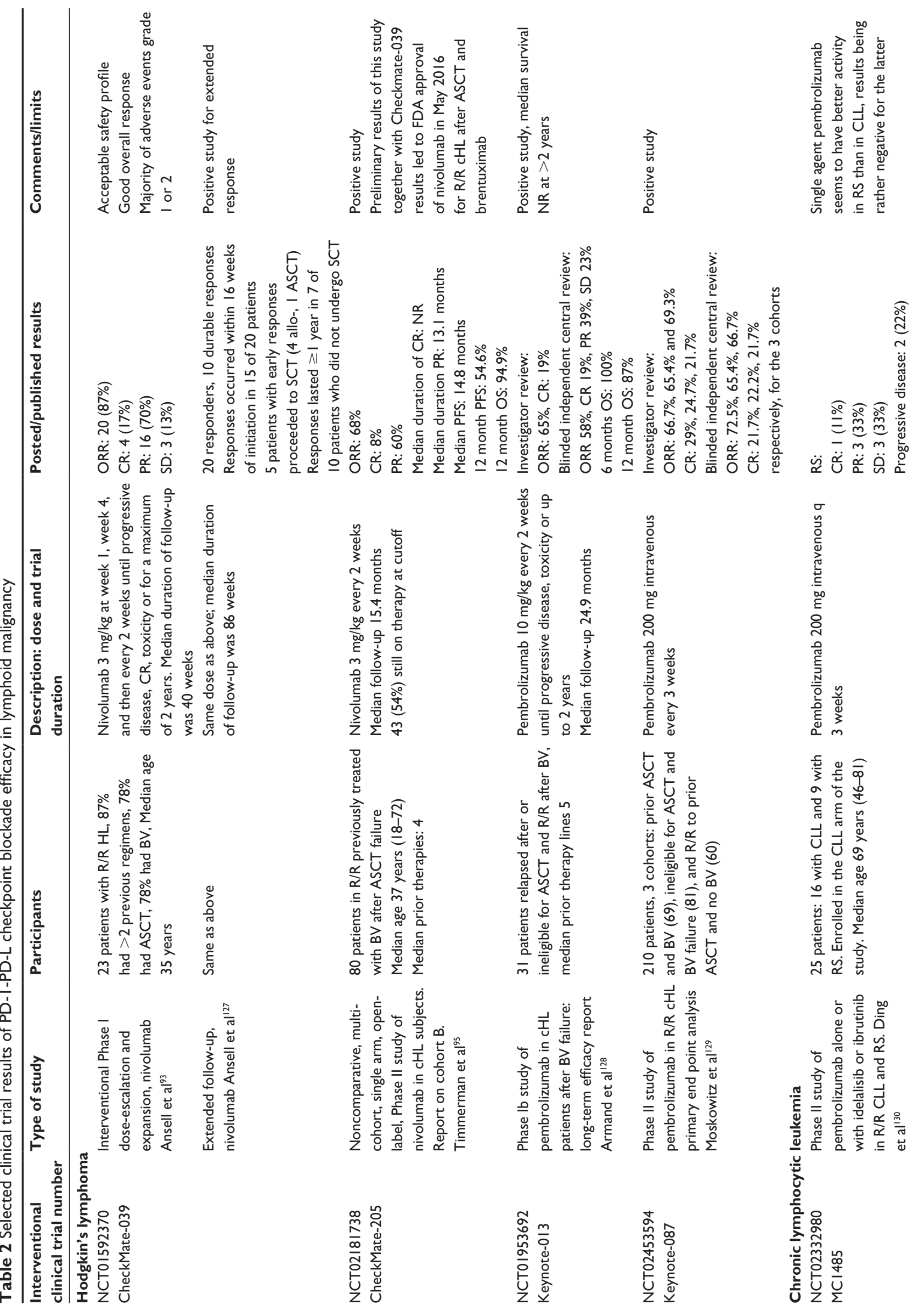



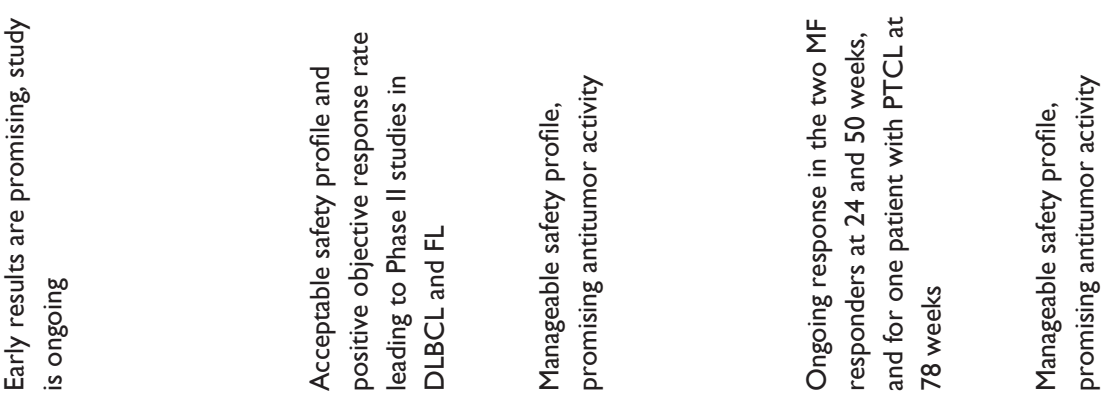

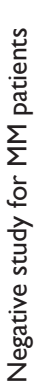
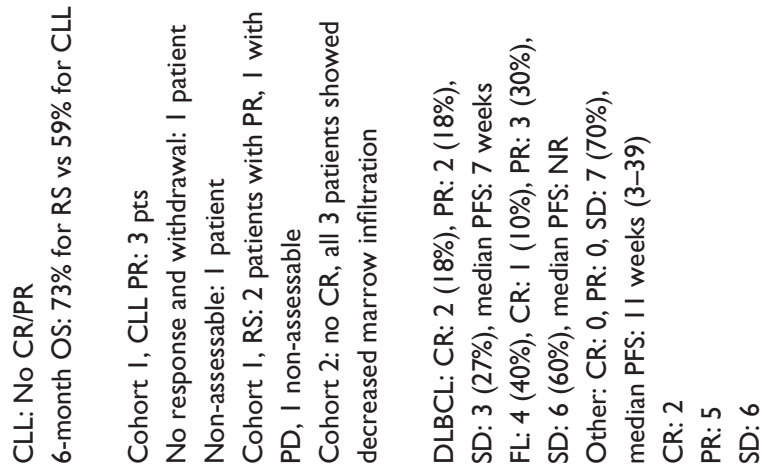

ㅇํ워

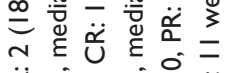

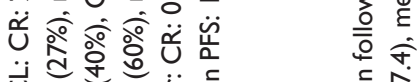

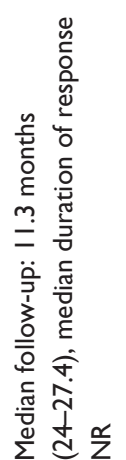

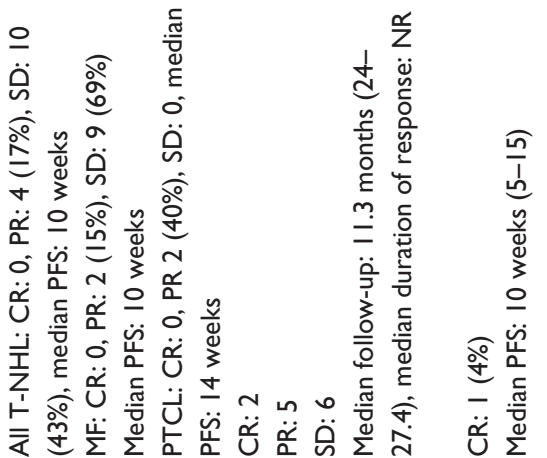
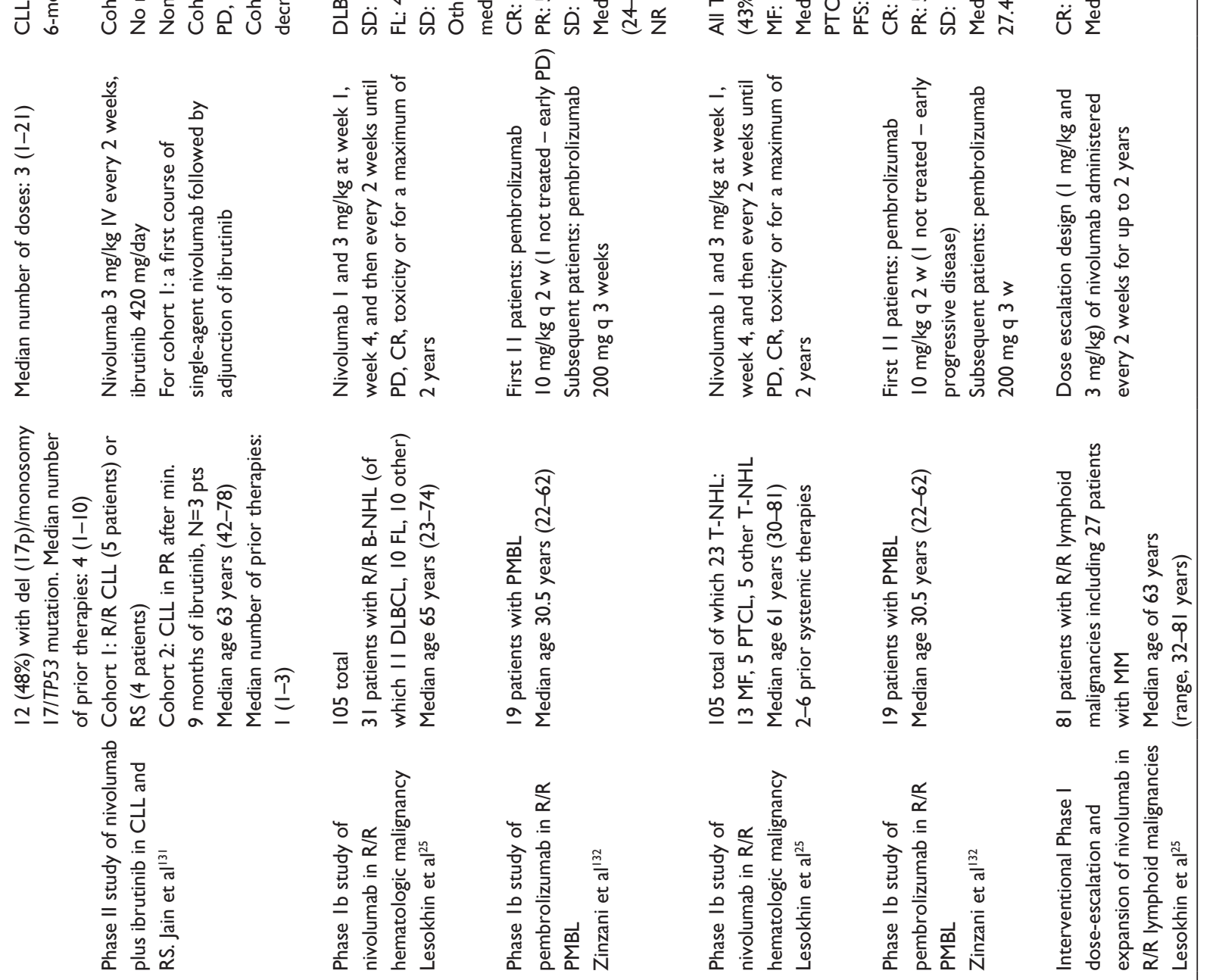

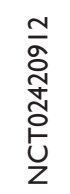

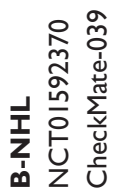

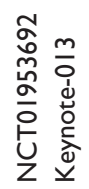
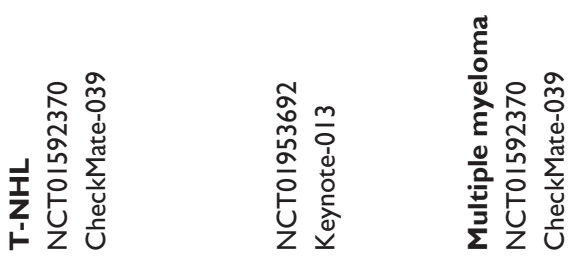


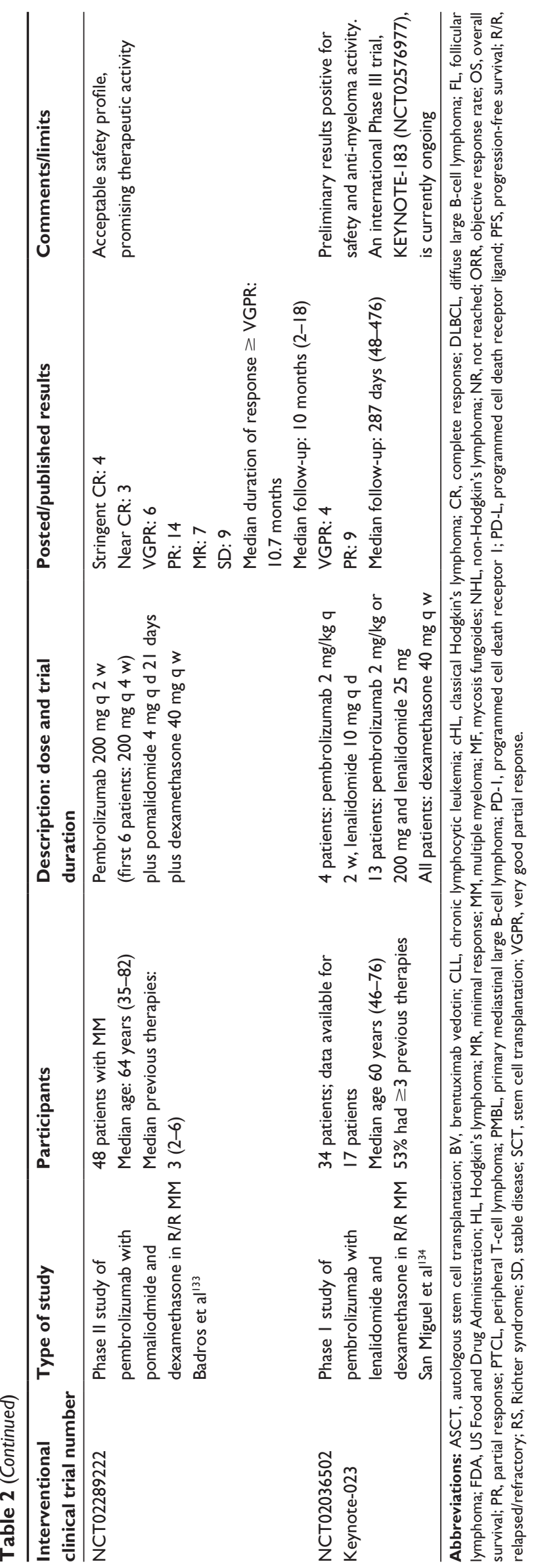

and leukemic cells are present in lymph nodes proliferation centers, suggesting their probable interaction and involvement in CLL pathogenesis.

A study on the effects of early in vivo PD-L1 blockade in a mouse model of CLL showed that administration of antiPD-L1 antibodies prevented disease progression. Decreased spleen sizes were observed, as well as changes in the tumor load and peripheral blood lymphocytosis. PD-L1 blockade prevented CD8:CD4 ratio inversion, $\mathrm{T}$ cell exhaustion, and determined increased CD8 cytotoxicity, growth fraction, in vivo proliferation, and CD8 synapse formation. ${ }^{100-102}$

$\mathrm{PD}-1$ expression is found on $\mathrm{CD}^{+}$and $\mathrm{CD} 8^{+} \mathrm{T}$ cells, their proliferation being associated with a negative prognosis, ${ }^{99}$ while PD-L1 expression on leukemic cells and mononuclear cells in peripheral blood and bone marrow is higher in CLL patients than in healthy controls. ${ }^{66,103}$ Apparently, ligand expression does not correlate with age, sex, LDH levels, white blood cell count or disease stage. ${ }^{66}$ However, PD-L1 significantly correlates with PD-1, TIL number, and IFN- $\gamma$ levels, PD-1-PD-L1 interaction suppressing intratumoral cytokine production, and ligand blockade stimulating IFN- $\gamma$ secretion through a negative feedback mechanism. ${ }^{66,76}$

Rusak et al reported that patients with advanced stage CLL have a considerably increased number of $\mathrm{PD} 1^{+} \mathrm{CD} 4^{+} \mathrm{T}$ cells in the peripheral blood compared to patients with incipient stages of the disease. ${ }^{104}$ Also, patients with lower levels of these lymphocytes achieved CR more frequently through PD-1 blockade, suggesting that the number of $\mathrm{PD} 1^{+} \mathrm{CD} 4^{+} \mathrm{T}$ cells correlates with the response obtained with this immunotherapy approach. These findings suggest that quantitative flow cytometric evaluation of $\mathrm{PD} 1{ }^{+} \mathrm{CD} 4^{+} \mathrm{T}$ cells could be used for prognostic purposes in newly diagnosed patients. ${ }^{104}$

\section{Non-Hodgkin lymphoma}

PD-1-PD-L blockade is under investigation in various types of NHL, based on evidence of frequent expression of PD-1, PD-L1, and PD-L2 in lymphoid malignancies. Cancer cells drive changes in the host immune response to generate unique microenvironments that promote cancer cell growth. The PD-1-PD-L1 interaction represents an important cause of lymphoma induced T-cell defects, causing changes in T-cell subsets, their effector function, expression of surface molecules, and gene expression profiles. Studies on FL and DLBCL found overexpression of 25 immune escape genes including the ones involved in PD-1-PD-L and CTLA-4 inhibitory axis, the LAG3 and TIM3/galectin T-cell exhaustion axis. ${ }^{68}$ Expression of these genes and proteins is considerably higher in DLBCL than in FL. Detectable circulating soluble PD-L1 was reported in DLBCL, and was associated with 
a poor prognosis. ${ }^{105}$ In a Phase I study of the anti-PD-1 nivolumab in patients with relapsed or refractory $\mathrm{T}$ and B-cell lymphomas ORR were $40 \%$ in patients with $\mathrm{FL}$, $36 \%$ in DLBCL, $15 \%$ in mycosis fungoides (MF) and $40 \%$ in peripheral T-cell lymphoma (PTCL). In the same study it was discovered that malignant cells from MF expressed high levels of PD-L2 and fluorescence in situ hybridization assays revealed chromosomal rearrangements (disomy 9p, polysomy 9p, and PD-L2 translocation), responsible for the ligand overexpression. ${ }^{25}$ Results of clinical trials of PD- 1 axis blockade in NHL are summarized in Table 2.

\section{Diffuse large B-cell lymphoma}

PD-L1 is highly expressed by DLBCL ( $>60 \%$ of cases), as compared to other solid tumors, such as melanoma $(30 \%)$ or nonsmall cell lung cancer $(25 \%-36 \%) .{ }^{68} \mathrm{PD}-\mathrm{L} 1$ expression by lymphoma cells is considered an independent factor for the OS, being associated with a poor prognosis. The number of PD- $1^{+}$TILs is associated with PD-L1 ${ }^{+}$lymphoma cells and PD-L1 ${ }^{+}$stromal cells, suggesting a role for the PD-1-PD-L1 pathway in the tumor microenvironment. ${ }^{78}$

Pidilizumab, a humanized IgG1 monoclonal antibody, was initially developed as an anti-PD-1 antibody and was the first one to be evaluated in lymphoid malignancies. Phases I and II studies in DLBCL and FL showed promising results, prompting the development of further anti-PD-1 antibodies. ${ }^{100}$ A multicenter Phase II clinical trial where pidilizumab was administered to patients with relapsed or refractory DLBCL after ASCT reported a 16 month PFS of $72 \%$. The reported overall response rate among patients with measurable disease after ASCT was 51\%, including 34\% CRs and $17 \%$ partial remissions. ${ }^{73}$ The PFS after posttransplant pidilizumab administration of $72 \%$ compares favorably to the PFS of $52 \%$ obtained after ASCT alone, in a cohort of autografted patients with chemosensitive DLBCL. ${ }^{52,73}$ Interestingly, by the end of 2015, the manufacturer of pidilizumab announced that the drug was no longer to be regarded as a PD-1 inhibitor. However, trials of pidilizumab in lymphoma yielded encouraging results and will go on, despite the mechanisms of the immune regulatory action of the drug not being precisely known.

Quan et al evaluated the efficacy of PD-1 blockade in Epstein-Barr virus (EBV)-associated DLBCL (EBV ${ }^{+}$ DLBCL), an aggressive lymphoma, highly resistant to current treatments and a potential target for immunotherapy. The number of effector/memory PD- $1^{+} \mathrm{T}$ cells is more elevated in the lymph nodes than in the peripheral blood, suggesting the immune suppressive effect of the tumor microenvironment in $\mathrm{DLBCL}$. $\mathrm{CD} 8^{+} \mathrm{PD}-1^{+}$and $\mathrm{CD} 4^{+} \mathrm{PD}-1^{+} \mathrm{T}$ cells also expressed CTLA-4, marker of T cell exhaustion. Lymphoma cells upregulate PD-1 expression on T cells and inhibit their proliferation and secretion of IL-2, IFN- $\gamma$, tumor necrosis factor- $\alpha$ (TNF- $\alpha$ ) and IL-10. PD-1 blockade reversed these effects, increasing T-cell proliferation and cytokine secretion. Also, it was shown in vitro that PD-1 blockade is more potent in $\mathrm{EBV}^{+}$than in $\mathrm{EBV}^{-}$DLBCL. ${ }^{81} \mathrm{~A}^{-}$French multicenter randomized trial in DLBCL patients receiving standard chemoimmunotherapy versus high-dose therapy revealed that levels of sPD-L1, with a cutoff of $1.52 \mathrm{ng} / \mathrm{mL}$, had negative predictive value for OS, elevated levels being significantly correlated with a poorer prognosis in the standard chemoimmunotherapy arm, and suggesting a potential benefit of PD-1 axis blocking therapy in these patients. ${ }^{105}$

\section{Follicular lymphoma}

FL is a hematologic malignancy characterized by an indolent heterogeneous evolution, relapses alternating with remissions and a $7-10$ years median survival. In $10 \%-15 \%$ of the cases it behaves aggressively or transforms to DLBCL, leading to poor treatment response and short survival. ${ }^{59}$ Gene expression profile and immunophenotyping of nonmalignant cells from FL have highlighted the involvement of the microenvironment in the clinical evolution and treatment response. ${ }^{59}$ Unlike CLL, where T cell defects also appear in the peripheral blood, in FL T cells are impaired only in the lymph nodes.

There is controversial evidence regarding PD-1 expression and its prognostic value in FL. Muenst et al showed that grade $1 \mathrm{FL}$ has a higher number of PD- $1^{+}$TILs than secondary DLBCL derived from FL. Also, PD- $1^{+}$TILs may influence tumor behavior in FL and secondary DLBCL arising from FL, being associated with improved disease specific survival in these entities. ${ }^{106}$

Carreras et al concluded that increased numbers of $\mathrm{CD}^{+}$and $\mathrm{CD} 8^{+}$lymphocytes are favorable prognostic markers. $\mathrm{PD}-1^{+}$cells and $\mathrm{T}_{\text {regs }}$ are localized in the tumoral follicular compartment, playing a role in inhibition of $\mathrm{T}$ cell activation and immunomodulation of the microenvironment PD- $1^{+}$TILs are an independent prognostic marker of survival in patients with FL and their number decreases with transformation to DLBCL. ${ }^{59}$ In a study on 70 FL patients selected for either very good or very poor outcome, $\mathrm{CD}^{+}$follicular cells were associated with poor outcome, whereas PD-1 ${ }^{+}$ follicular cells and CD $8^{+}$interfollicular cells were associated with a good outcome. As far as tumor-microenvironment cell ratios were concerned, high CD4/CD 8 and CD4 follicular/interfollicular ratios appeared to be markers of poor outcome. ${ }^{62}$ A study conducted by Myklebust et al showed that PD-L1 expression is present in histocytes, 
in T cell-rich areas between the follicles, playing an inhibitory role in T-cell activation. ${ }^{77}$ High numbers of tissue-infiltrating macrophages were associated with unfavorable evolution and TILs from FL have an impaired activity, probably mediated by the malignant $\mathrm{B}$ cells of the lymphoma. Follicular localization of $\mathrm{T}_{\text {regs }}$ correlated with poor clinical outcome and increased risk of transformation. ${ }^{77}$

FL microenvironment includes a variety of T-cell subsets that express PD-1: antitumor effector T cells (helper $\mathrm{CD}^{+} \mathrm{T}$ and cytotoxic $\mathrm{CD}^{+} \mathrm{T}$ cells), protumoral follicular helper $\mathrm{T}$ cells $\left(\mathrm{T}_{\mathrm{FH}}\right)$ and follicular regulatory $\mathrm{T}$ cells, with a role in suppressing lymphoma cells and $\mathrm{T}_{\mathrm{FH}}{ }^{107} \mathrm{~T}_{\mathrm{FH}}$ are localized in intrafollicular regions and highly express PD-1, whereas exhausted $\mathrm{T}$ cells reside in interfollicular areas and express low levels of PD-1. ${ }^{108}$ Therefore, inconsistency regarding the prognostic value of $\mathrm{PD}-1^{+} \mathrm{T}$ cells in $\mathrm{FL}$ is probably caused by the multiple types of cells expressing $\mathrm{PD}-1$ receptor and by the effects of the PD-1 blockade on every subset. ${ }^{107}$ Patients with higher numbers of PD- $1^{+}$effector T cells may have a positive response at anti-PD-1 antibody administration, whereas patients with higher numbers of $\mathrm{PD}-1^{+} \mathrm{T}_{\mathrm{FH}}$ may have no response or develop disease progression after PD-1 blockade. ${ }^{109}$

Reported clinical trial results showed promising results for nivolumab in $\mathrm{R} / \mathrm{R} \mathrm{FL}$, albeit not as good as in $\mathrm{cHL}$ (Table 2).

\section{Cutaneous T-cell lymphoma (CTCL)/ mycosis fungoides}

PD-1 is frequently expressed in the early stages of CTCL, where $>25 \%$ of atypical lymphocytes express the receptor. PD-1 expression diminishes in the tumor stage of the lymphoma and in cases of large cell transformation. PD-L1 is expressed by the majority of atypical lymphocytes during all stages of lymphoma evolution and increases with disease progression and large cell transformation. ${ }^{110}$ Therefore, administration of anti-PD-1 antibodies may restore the immune function of the lymphocytes and could be used in the early stages of CTCL, when PD-1 expression is the most pronounced. In more advanced stages when PD-L1 is highly expressed and the lymphoma is more aggressive, administration of anti-PD-L1 antibodies should improve the antitumor immunity. ${ }^{110}$

\section{Peripheral T-cell lymphoma}

PTCLs are malignancies derived from postthymic T-cells. The most common types include AITL and PTCL, not otherwise specified (NOS). Both AITL and PTCL are characterized by atypical lymphocytes in the paracortical zones of the lymph nodes. Results from a study on PD-1 expression in PTCL demonstrated that extrafollicular expansion of PD- $1^{+}$T cells was encountered in $93 \%$ of the AITL cases and $62 \%$ of PTCL. ${ }^{111}$

In another study all cases of AITL showed reactivity for PD-1, which is expressed on the cell surface and in the cytoplasm of neoplastic $\mathrm{CD}^{+} \mathrm{T}$ cells. In reactive lymph nodes, PD-1 expression is mainly localized in the germinal centers, similar to another marker encountered in AITL, CXCL13, a chemokine that distinguishes AITL from PTCL. ${ }^{67}$ However, studies showed that PD-1 can serve as a sensible, but not specific marker for the diagnosis of AITL and PTCL-NOS, because a similar abnormal PD-1 staining pattern is observed in nonmalignant diseases such as viral lymphadenitis, highlighting the importance of differential diagnosis in these situations. ${ }^{111,112}$

\section{Multiple myeloma}

$\mathrm{MM}$, an incurable B cell malignancy, is a monoclonal gammopathy characterized by neoplastic proliferation of plasma cells and their accumulation in the bone marrow, causing bone marrow failure, anemia, and osteolytic bone lesions with secondary hypercalcemia. Excessive production of monoclonal protein leads to predisposition to infection and systemic amyloidosis with organ failure (renal, heart, liver, and nervous system). ${ }^{113}$ The disease mainly affects the elderly and has a median survival of 4-5 years. ${ }^{114}$

$\mathrm{CD}_{138^{+}}$malignant plasma cells and tumor microenvironment cells such as myeloid-derived suppressor cells have an increased expression of PD-L1 compared with normal plasma cells, in which expression of this ligand is insignificant. ${ }^{115-118} \mathrm{PD}-\mathrm{L1}^{+}$plasma cells levels do not correlate with tumor burden, suggesting that the ligand expression is also influenced by factors from the microenvironment. Indeed, populations of dendritic cells accumulate in the bone marrow, express PD-L1 and affect T cell antitumor activity. ${ }^{119}$ Stromal cells upregulate PD-L1 levels on myeloma cells, stimulate their proliferation, and dampen the response to chemotherapy, accelerated disease progression being observed in patients with high PD-L1 expression. ${ }^{114,120}$

Myeloma cells accumulate and exert their action in the bone marrow. Their local immunosuppressive effect leads to the presence of a PD- $1^{+} \mathrm{T}$ cell population with higher dysfunction compared to circulating $\mathrm{T}$ cells, as shown in preclinical studies. ${ }^{23,116,121} \mathrm{PD}-1$ expression is also elevated on natural killer cells from myeloma patients compared to healthy controls. ${ }^{122}$ Direct interaction between the ligand 
present on myeloma cells and the receptor expressed by $\mathrm{T}$ and natural killer cells inhibits the antitumor immune response and contributes to chemotherapy resistance, while administration of an anti-PD-1 antibody stimulates lymphocyte cytolytic activity against malignant cells and reduces the tumor growth induced by stromal cells. ${ }^{122-124}$

In myeloma patients' serum, high concentrations of soluble PD-L1 were identified and this fraction might also interact with PD-1, contributing to the immune suppression. Correlations between soluble PD-L1, disease aggressiveness, and poorer responses to treatment have been established. A value over $2.78 \mathrm{ng} / \mathrm{mL}$ was proposed as an independent prognosis factor for a shorter PFS. ${ }^{123}$

Administration of anti-PD-L1 antibodies after chemotherapy overthrows tumor-induced immunosuppression and restores lymphocyte production of IFN- $\gamma$ consecutive to tumor antigen stimulation. When both $\mathrm{CD} 4^{+}$and $\mathrm{CD} 8^{+} \mathrm{T}$ cells were reactivated, PD-L1 blockade determined successful myeloma eradication in preclinical studies. ${ }^{125,126}$

\section{Conclusion}

Like with other cancers, immune checkpoint blockade inhibitors are a promising immunotherapeutic option in hematologic malignancies, and PD-1-PD-L1 axis blockers are the most investigated candidates to date. While there are over 600 ongoing clinical trials of PD-1-PD-L axis blockade in oncology, only a small proportion of these are investigating hematologic cancers. Nevertheless, results in hematologic malignancies are extremely promising, and the US FDA granted accelerated approval for nivolumab in $\mathrm{cHL}$ in 2016. Fuelled by these results, the number of clinical trials is increasing at a high rate, and many drugs in this class are currently under development. With more early trial results published at this high rate, we expect that immune checkpoint blockade will soon become an integral and well represented target, and feature as part of the management of hematologic malignancy.

\section{Acknowledgments}

This work was supported by a grant from the Romanian National Authority for Scientific Research and Innovation, CNCS - UEFISCDI, project number PN-II-RU-TE-20144-2074. We thank Dr Michael Edwards of Imperial College for his kind support in the English language polishing of this manuscript.

\section{Disclosure}

The authors report no conflicts of interest in this work.

\section{References}

1. McDermott DF, Atkins MB. PD-1 as a potential target in cancer therapy. Cancer Med. 2013;2(5):662-673.

2. Ishida Y, Agata Y, Shibahara K, Honjo T. Induced expression of PD-1, a novel member of the immunoglobulin gene superfamily, upon programmed cell death. EMBO J. 1992;11(11):3887-3895.

3. Bryan LJ, Gordon LI. Blocking tumor escape in hematologic malignancies: the anti-PD-1 strategy. Blood Rev. 2015;29(1):25-32.

4. Agata Y, Kawasaki A, Nishimura H, et al. Expression of the PD-1 antigen on the surface of stimulated mouse $\mathrm{T}$ and $\mathrm{B}$ lymphocytes. Int Immunol. 1996;8(5):765-772.

5. Zheng P, Zhou Z. Human cancer immunotherapy with PD-1/PD-L1 blockade. Biomark Cancer. 2015;7(Suppl 2):15-18.

6. Ghiotto M, Gauthier L, Serriari N, et al. PD-L1 and PD-L2 differ in their molecular mechanisms of interaction with PD-1. Int Immunol. 2010; 22(8):651-660.

7. Brahmer JR, Drake CG, Wollner I, et al. Phase I study of single-agent anti-programmed death-1 (MDX-1106) in refractory solid tumors: safety, clinical activity, pharmacodynamics, and immunologic correlates. J Clin Oncol. 2010;28(19):3167-3175.

8. Liang SC, Latchman YE, Buhlmann JE, et al. Regulation of PD-1, PD-L1, and PD-L2 expression during normal and autoimmune responses. Eur J Immunol. 2003;33(10):2706-2716.

9. Stanciu LA, Bellettato CM, Laza-Stanca V, Coyle AJ, Papi A, Johnston SL. Expression of programmed death-1 ligand (PD-L) 1, PD-L2, B7-H3, and inducible costimulator ligand on human respiratory tract epithelial cells and regulation by respiratory syncytial virus and type 1 and 2 cytokines. J Infect Dis. 2006;193(3):404-412.

10. Zdrenghea MT, Johnston SL. Role of PD-L1/PD-1 in the immune response to respiratory viral infections. Microbes Infect. 2012;14(6):495-499.

11. Lesterhuis WJ, Steer H, Lake RA. PD-L2 is predominantly expressed by Th2 cells. Mol Immunol. 2011;49(1-2):1-3.

12. Youngnak P, Kozono Y, Kozono H, et al. Differential binding properties of B7-H1 and B7-DC to programmed death-1. Biochem Biophys Res Coтmun. 2003;307(3):672-677.

13. Fife BT, Pauken KE, Eagar TN, et al. Interactions between PD-1 and PD-L1 promote tolerance by blocking the TCR-induced stop signal. Nat Immunol. 2009;10(11):1185-1192.

14. Keir ME, Liang SC, Guleria I, et al. Tissue expression of PD-L1 mediates peripheral T cell tolerance. J Exp Med. 2006;203(4):883-895.

15. Latchman YE, Liang SC, Wu Y, et al. PD-L1-deficient mice show that PD-L1 on T cells, antigen-presenting cells, and host tissues negatively regulates T cells. Proc Natl Acad Sci U S A. 2004;101(29): 10691-10696.

16. Yamazaki T, Akiba H, Iwai H, et al. Expression of programmed death 1 ligands by murine T cells and APC. J Immunol. 2002;169(10): 5538-5545.

17. Shi L, Chen S, Yang L, Li Y. The role of PD-1 and PD-L1 in T-cell immune suppression in patients with hematological malignancies. J Hematol Oncol. 2013;6(1):74.

18. Boni C, Fisicaro P, Valdatta C, et al. Characterization of hepatitis B virus (HBV)-specific T-cell dysfunction in chronic HBV infection. $J$ Virol. 2007;81(8):4215-4225.

19. Li Z, Li N, Li F, et al. Immune checkpoint proteins PD-1 and TIM-3 are both highly expressed in liver tissues and correlate with their gene polymorphisms in patients with HBV-related hepatocellular carcinoma. Medicine (Baltimore). 2016;95(52):e5749.

20. Day CL, Kaufmann DE, Kiepiela P, et al. PD-1 expression on HIVspecific $\mathrm{T}$ cells is associated with T-cell exhaustion and disease progression. Nature. 2006;443(7109):350-354.

21. Sehgal A, Whiteside TL, Boyiadzis M. Programmed death-1 checkpoint blockade in acute myeloid leukemia. Expert Opin Biol Ther. 2015; 15(8):1191-1203.

22. Brown JA, Dorfman DM, Ma FR, et al. Blockade of programmed death-1 ligands on dendritic cells enhances $\mathrm{T}$ cell activation and cytokine production. J Immunol. 2003;170(3):1257-1266. 
23. Hamanishi J, Mandai M, Iwasaki M, et al. Programmed cell death 1 ligand 1 and tumor-infiltrating CD8+ T lymphocytes are prognostic factors of human ovarian cancer. Proc Natl Acad Sci U S A. 2007; 104(9):3360-3365.

24. Nomi T, Sho M, Akahori T, et al. Clinical significance and therapeutic potential of the programmed death-1 ligand/programmed death-1 pathway in human pancreatic cancer. Clin Cancer Res. 2007;13(7): 2151-2157.

25. Lesokhin AM, Ansell SM, Armand P, et al. Nivolumab in Patients With Relapsed or Refractory Hematologic Malignancy: Preliminary Results of a Phase Ib Study. J Clin Oncol. 2016;34(23):2698-2704.

26. Hamanishi J, Mandai M, Matsumura N, Abiko K, Baba T, Konishi I. PD-1/PD-L1 blockade in cancer treatment: perspectives and issues. Int J Clin Oncol. 2016;21(3):462-473.

27. Blank C, Brown I, Peterson AC, et al. PD-L1/B7H-1 inhibits the effector phase of tumor rejection by $\mathrm{T}$ cell receptor (TCR) transgenic CD8+ T cells. Cancer Res. 2004;64(3):1140-1145.

28. Ahmadzadeh M, Johnson LA, Heemskerk B, et al. Tumor antigenspecific CD8 T cells infiltrating the tumor express high levels of PD-1 and are functionally impaired. Blood. 2009;114(8):1537-1544.

29. Li J, Jie HB, Lei Y, et al. PD-1/SHP-2 inhibits Tc1/Th1 phenotypic responses and the activation of $\mathrm{T}$ cells in the tumor microenvironment. Cancer Res. 2015;75(3):508-518.

30. Bottai G, Raschioni C, Losurdo A, et al. An immune stratification reveals a subset of PD-1/LAG-3 double-positive triple-negative breast cancers. Breast Cancer Res. 2016;18(1):121.

31. Chapon M, Randriamampita C, Maubec E, et al. Progressive upregulation of PD-1 in primary and metastatic melanomas associated with blunted TCR signaling in infiltrating T lymphocytes. J Invest Dermatol. 2011;131(6):1300-1307.

32. Muenst S, Soysal SD, Gao F, Obermann EC, Oertli D, Gillanders WE. The presence of programmed death 1 (PD-1)-positive tumor-infiltrating lymphocytes is associated with poor prognosis in human breast cancer. Breast Cancer Res Treat. 2013;139(3):667-676.

33. Wei F, Zhong S, Ma Z, et al. Strength of PD-1 signaling differentially affects T-cell effector functions. Proc Natl Acad Sci US A. 2013;110(27): E2480-E2489.

34. Zhang Y, Huang S, Gong D, Qin Y, Shen Q. Programmed death-1 upregulation is correlated with dysfunction of tumor-infiltrating CD8+ T lymphocytes in human non-small cell lung cancer. Cell Mol Immunol. 2010;7(5):389-395.

35. Cimino-Mathews A, Thompson E, Taube JM, et al. PD-L1 (B7-H1) expression and the immune tumor microenvironment in primary and metastatic breast carcinomas. Hum Pathol. 2016;47(1):52-63.

36. Dong H, Strome SE, Salomao DR, et al. Tumor-associated B7-H1 promotes T-cell apoptosis: a potential mechanism of immune evasion. Nat Med. 2002;8(8):793-800.

37. Brusa D, Serra S, Coscia M, et al. The PD-1/PD-L1 axis contributes to T-cell dysfunction in chronic lymphocytic leukemia. Haematologica. 2013;98(6):953-963.

38. Yamamoto R, Nishikori M, Kitawaki T, et al. PD-1-PD-1 ligand interaction contributes to immunosuppressive microenvironment of Hodgkin lymphoma. Blood. 2008;111(6):3220-3224.

39. Iwai Y, Ishida M, Tanaka Y, Okazaki T, Honjo T, Minato N. Involvement of PD-L1 on tumor cells in the escape from host immune system and tumor immunotherapy by PD-L1 blockade. Proc Natl Acad Sci U S A. 2002;99(19):12293-12297.

40. Telcian AG, Laza-Stanca V, Edwards MR, et al. RSV-induced bronchial epithelial cell PD-L1 expression inhibits CD8+ T cell nonspecific antiviral activity. J Infect Dis. 2011;203(1):85-94.

41. Taube JM, Klein A, Brahmer JR, et al. Association of PD-1, PD-1 ligands, and other features of the tumor immune microenvironment with response to anti-PD-1 therapy. Clin Cancer Res. 2014;20(19): 5064-5074.

42. Zhang Y, Wang L, Li Y, et al. Protein expression of programmed death 1 ligand 1 and ligand 2 independently predict poor prognosis in surgically resected lung adenocarcinoma. Onco Targets Ther. 2014;7:567-573.
43. Grosso J HC, Inzunza D, Cardona DM, Simon JS, Gupta AK, Sankar V. Association of tumor PD-L1 expression and immune biomarkers with clinical activity in patients (pts) with advanced solid tumors treated with nivolumab. J Clin Oncol. 2013;31(Suppl):Abstract 3016.

44. Muenst S, Schaerli AR, Gao F, et al. Expression of programmed death ligand 1 (PD-L1) is associated with poor prognosis in human breast cancer. Breast Cancer Res Treat. 2014;146(1):15-24.

45. Zeng Z, Shi F, Zhou L, et al. Upregulation of circulating PD-L1/PD-1 is associated with poor post-cryoablation prognosis in patients with $\mathrm{HBV}$ related hepatocellular carcinoma. PLoS One. 2011;6(9):e23621.

46. Droeser RA, Hirt C, Viehl CT, et al. Clinical impact of programmed cell death ligand 1 expression in colorectal cancer. Eur J Cancer. 2013; 49(9):2233-2242.

47. McDermott DF, Sosman JA, Sznol M, et al. Atezolizumab, an antiprogrammed death-ligand 1 antibody, in metastatic renal cell carcinoma: long-term safety, clinical activity, and Immune Correlates From a Phase Ia Study. J Clin Oncol. 2016;34(8):833-842.

48. Bellmunt J, Mullane SA, Werner L, et al. Association of PD-L1 expression on tumor-infiltrating mononuclear cells and overall survival in patients with urothelial carcinoma. Ann Oncology. 2015;26(4):812-817.

49. Herbst RS, Soria JC, Kowanetz M, et al. Predictive correlates of response to the anti-PD-L1 antibody MPDL3280A in cancer patients. Nature. 2014;515(7528):563-567.

50. Topalian SL, Hodi FS, Brahmer JR, et al. Safety, activity, and immune correlates of anti-PD-1 antibody in cancer. $N$ Engl J Med. 2012; 366(26):2443-2454.

51. Robert C, Long GV, Brady B, et al. Nivolumab in previously untreated melanoma without BRAF mutation. $N$ Engl J Med. 2015;372(4): 320-330.

52. Armand P. Immune checkpoint blockade in hematologic malignancies. Blood. 2015;125(22):3393-3400.

53. Garon EB, Rizvi NA, Hui R, et al. Pembrolizumab for the treatment of non-small-cell lung cancer. N Engl J Med. 2015;372(21):2018-2028.

54. Rizvi NA, Mazieres J, Planchard D, et al. Activity and safety of nivolumab, an anti-PD-1 immune checkpoint inhibitor, for patients with advanced, refractory squamous non-small-cell lung cancer (CheckMate 063): a phase 2, single-arm trial. Lancet Oncol. 2015;16(3):257-265.

55. Motzer RJ, Rini BI, McDermott DF, et al. Nivolumab for metastatic renal cell carcinoma: results of a randomized phase II trial. J Clin Oncol. 2015;33(13):1430-1437.

56. Carbognin L, Pilotto S, Milella M, et al. Differential activity of nivolumab, pembrolizumab and MPDL3280A according to the tumor expression of programmed death-ligand-1 (PD-L1): sensitivity analysis of trials in melanoma, lung and genitourinary cancers. PLoS One. 2015; 10(6): 0130142.

57. Bryan LJ, Gordon LI. Releasing the brake on the immune system: the PD-1 strategy for hematologic malignancies. Oncology. 2015;29(6): 431-439.

58. Muenst S, Hoeller S, Dirnhofer S, Tzankov A. Increased programmed death-1+ tumor-infiltrating lymphocytes in classical Hodgkin lymphoma substantiate reduced overall survival. Hum Pathol. 2009;40(12): $1715-1722$.

59. Carreras J, Lopez-Guillermo A, Roncador G, et al. High numbers of tumor-infiltrating programmed cell death 1-positive regulatory lymphocytes are associated with improved overall survival in follicular lymphoma. J Clin Oncol. 2009;27(9):1470-1476.

60. Takahashi N, Iwasa S, Sasaki Y, et al. Serum levels of soluble programmed cell death ligand 1 as a prognostic factor on the first-line treatment of metastatic or recurrent gastric cancer. J Cancer Res Clin Oncol. 2016;142(8):1727-1738.

61. Finkelmeier F, Canli O, Tal A, et al. High levels of the soluble programmed death-ligand (sPD-L1) identify hepatocellular carcinoma patients with a poor prognosis. Eur J Cancer. 2016;59:152-159.

62. Wahlin BE, Aggarwal M, Montes-Moreno S, et al. A unifying microenvironment model in follicular lymphoma: outcome is predicted by programmed death-1 - positive, regulatory, cytotoxic, and helper T cells and macrophages. Clin Cancer Res. 2010;16(2):637-650. 
63. Ha H, Nam AR, Bang JH, et al. Soluble programmed death-ligand 1 (sPDL1) and neutrophil-to-lymphocyte ratio (NLR) predicts survival in advanced biliary tract cancer patients treated with palliative chemotherapy. Oncotarget. 2016;7(47):76604-76612.

64. Bang YJ, Chung HC, Shankaran V, et al. LBA-04Clinical outcomes and their correlation with gene expression in patients with advanced gastric cancer treated with pembrolizumab (MK-3475): KEYNOTE-012. Ann Oncol. 2015;26(Suppl 4):iv118-iv118.

65. Timmerman J. Hematologic cancers break down a 'checkpoint': targeting the PD-1/PD-L1 axis. Oncology (Williston Park). 2015;29(6): 440-441.

66. Grzywnowicz M, Karczmarczyk A, Skorka K, et al. Expression of programmed death 1 ligand in different compartments of chronic lymphocytic leukemia. Acta Haematol. 2015;134(4):255-262.

67. Yu H, Shahsafaei A, Dorfman DM. Germinal-center T-helper-cell markers PD-1 and CXCL13 are both expressed by neoplastic cells in angioimmunoblastic T-cell lymphoma. Am J Clin Pathol. 2009;131(1):33-41.

68. Laurent C, Charmpi K, Gravelle P, et al. Several immune escape patterns in non-Hodgkin's lymphomas. Oncoimmunology. 2015;4(8): e1026530.

69. Chen BJ, Chapuy B, Ouyang J, et al. PD-L1 expression is characteristic of a subset of aggressive B-cell lymphomas and virus-associated malignancies. Clin Cancer Res. 2013;19(13):3462-3473.

70. Yang H, Bueso-Ramos C, DiNardo C, et al. Expression of PD-L1, PD-L2, PD-1 and CTLA4 in myelodysplastic syndromes is enhanced by treatment with hypomethylating agents. Leukemia. 2014;28(6): 1280-1288.

71. Kronig H, Kremmler L, Haller B, et al. Interferon-induced programmed death-ligand 1 (PD-L1/B7-H1) expression increases on human acute myeloid leukemia blast cells during treatment. Eur J Haematol. 2014; 92(3): 195-203.

72. Norde WJ, Maas F, Hobo W, et al. PD-1/PD-L1 interactions contribute to functional T-cell impairment in patients who relapse with cancer after allogeneic stem cell transplantation. Cancer Res. 2011;71(15): 5111-5122.

73. Armand P, Nagler A, Weller EA, et al. Disabling immune tolerance by programmed death-1 blockade with pidilizumab after autologous hematopoietic stem-cell transplantation for diffuse large B-cell lymphoma: results of an international phase II trial. J Clin Oncol. 2013;31(33): 4199-4206.

74. Vranic S, Ghosh N, Kimbrough J, et al. PD-L1 Status in Refractory Lymphomas. PLoS One. 2016;11(11):e0166266.

75. Wilcox RA, Feldman AL, Wada DA, et al. B7-H1 (PD-L1, CD274) suppresses host immunity in T-cell lymphoproliferative disorders Blood. 2009;114(10):2149-2158.

76. Andorsky DJ, Yamada RE, Said J, Pinkus GS, Betting DJ, Timmerman JM. Programmed death ligand 1 is expressed by nonhodgkin lymphomas and inhibits the activity of tumor-associated T cells. Clin Cancer Res. 2011;17(13):4232-4244.

77. Myklebust JH, Irish JM, Brody J, et al. High PD-1 expression and suppressed cytokine signaling distinguish $\mathrm{T}$ cells infiltrating follicular lymphoma tumors from peripheral T cells. Blood. 2013;121(8): 1367-1376.

78. Kiyasu J, Miyoshi H, Hirata A, et al. Expression of programmed cell death ligand 1 is associated with poor overall survival in patients with diffuse large B-cell lymphoma. Blood. 2015;126(19):2193-2201.

79. Kwon D, Kim S, Kim PJ, et al. Clinicopathological analysis of programmed cell death 1 and programmed cell death ligand 1 expression in the tumour microenvironments of diffuse large B cell lymphomas. Histopathology. 2016;68(7):1079-1089.

80. Green MR, Rodig S, Juszczynski P, et al. Constitutive AP-1 activity and EBV infection induce PD-L1 in Hodgkin lymphomas and posttransplant lymphoproliferative disorders: implications for targeted therapy. Clin Cancer Res. 2012;18(6):1611-1618.

81. Quan L, Chen X, Liu A, et al. PD-1 blockade can restore functions of T-cells in epstein-barr virus-positive diffuse large B-cell lymphoma In vitro. PLoS One. 2015;10(9):e0136476.
82. Rosenwald A, Wright G, Leroy K, et al. Molecular diagnosis of primary mediastinal B cell lymphoma identifies a clinically favorable subgroup of diffuse large B cell lymphoma related to Hodgkin lymphoma. J Exp Med. 2003;198(6):851-862.

83. Green MR, Monti S, Rodig SJ, et al. Integrative analysis reveals selective 9p24.1 amplification, increased PD-1 ligand expression, and further induction via JAK2 in nodular sclerosing Hodgkin lymphoma and primary mediastinal large B-cell lymphoma. Blood. 2010;116(17): 3268-3277.

84. Bentz M, Barth TF, Bruderlein S, et al. Gain of chromosome arm 9p is characteristic of primary mediastinal B-cell lymphoma (MBL): comprehensive molecular cytogenetic analysis and presentation of a novel MBL cell line. Genes Chromosomes Cancer. 2001;30(4): 393-401.

85. Chapuy B, Roemer MG, Stewart C, et al. Targetable genetic features of primary testicular and primary central nervous system lymphomas. Blood. 2016;127(7):869-881.

86. Bi XW, Wang $\mathrm{H}$, Zhang WW, et al. PD-L1 is upregulated by EBV-driven LMP1 through NF-kappaB pathway and correlates with poor prognosis in natural killer/T-cell lymphoma. J Hematol Oncol. 2016;9(1):109.

87. Wang H, Wang L, Liu WJ, et al. High post-treatment serum levels of soluble programmed cell death ligand 1 predict early relapse and poor prognosis in extranodal NK/T cell lymphoma patients. Oncotarget. 2016;7(22):33035-33045.

88. Kim WY, Jung HY, Nam SJ, et al. Expression of programmed cell death ligand 1 (PD-L1) in advanced stage EBV-associated extranodal NK/T cell lymphoma is associated with better prognosis. Virchows Arch. 2016;469(5):581-590.

89. Kinosada H, Yasunaga JI, Shimura K, et al. HTLV-1 bZIP factor enhances T-Cell proliferation by impeding the suppressive signaling of co-inhibitory receptors. PLoS Pathog. 2017;13(1):e1006120.

90. Shimauchi T, Kabashima K, Nakashima D, et al. Augmented expression of programmed death-1 in both neoplastic and non-neoplastic CD4+ T-cells in adult T-cell leukemia/lymphoma. Inter J Cancer. 2007;121(12):2585-2590.

91. Kozako T, Yoshimitsu M, Fujiwara H, et al. PD-1/PD-L1 expression in human T-cell leukemia virus type 1 carriers and adult T-cell leukemia/ lymphoma patients. Leukemia. 2009;23(2):375-382.

92. Yasuma K, Yasunaga J, Takemoto K, et al. HTLV-1 bZIP factor impairs anti-viral immunity by inducing co-inhibitory molecule, $\mathrm{T}$ cell immunoglobulin and ITIM domain (TIGIT). PLoS Pathog. 2016;12(1):e1005372.

93. Ansell SM, Lesokhin AM, Borrello I, et al. PD-1 blockade with nivolumab in relapsed or refractory Hodgkin's lymphoma. $N$ Engl J Med. 2015;372(4):311-319.

94. Younes A, Andreas Engert AS, Margaret Shipp, et al. Checkmate 205: A Phase 2 Study of Nivolumab in Patients With Classical Hodgkin Lymphoma Following Autologous Stem Cell Transplantation and Brentuximab Vedotin. Copenhagen, Denmark: EHA21; 2016.

95. Timmerman JM, Engert A, Younes A, et al. Checkmate 205 update with minimum 12-Month Follow up: a phase 2 study of nivolumab in patients with relapsed/refractory classical Hodgkin lymphoma. Blood. 2016;128(22):1110-1110.

96. Herishanu Y, Katz BZ, Lipsky A, Wiestner A. Biology of chronic lymphocytic leukemia in different microenvironments: clinical and therapeutic implications. Hematol Oncol Clin North Am. 2013;27(2):173-206.

97. Ramsay AD, Rodriguez-Justo M. Chronic lymphocytic leukaemia the role of the microenvironment pathogenesis and therapy. $\mathrm{Br} J$ Haematol. 2013;162(1):15-24.

98. Rossmann ED, Jeddi-Tehrani M, Osterborg A, Mellstedt H. T-cell signaling and costimulatory molecules in B-chronic lymphocytic leukemia (B-CLL): an increased abnormal expression by advancing stage. Leukemia. 2003;17(11):2252-2254.

99. Nunes C, Wong R, Mason M, Fegan C, Man S, Pepper C. Expansion of a CD8(+)PD-1(+) replicative senescence phenotype in early stage CLL patients is associated with inverted CD4:CD8 ratios and disease progression. Clin Cancer Res. 2012;18(3):678-687. 
100. Batlevi CL, Matsuki E, Brentjens RJ, Younes A. Novel immunotherapies in lymphoid malignancies. Nat Rev Clin Oncol. 2016;13(1): $25-40$.

101. Gribben J. Tumor microenvironment: a rational therapeutic target for lymphomas EHA Learning Center. Presented at the 15 th symposium of the EHA; June 14; 2015.

102. Berger R, Rotem-Yehudar R, Slama G, et al. Phase I safety and pharmacokinetic study of CT-011, a humanized antibody interacting with PD-1, in patients with advanced hematologic malignancies. Clin Cancer Res. 2008;14(10):3044-3051.

103. Grzywnowicz M, Zaleska J, Mertens D, et al. Programmed death-1 and its ligand are novel immunotolerant molecules expressed on leukemic B cells in chronic lymphocytic leukemia. PLoS One. 2012; 7(4):e35178.

104. Rusak M, Eljaszewicz A, Bolkun L, et al. Prognostic significance of PD-1 expression on peripheral blood CD4+ T cells in patients with newly diagnosed chronic lymphocytic leukemia. Pol Arch Med Wewn. 2015;125(7-8):553-559.

105. Rossille D, Gressier M, Damotte D, et al. High level of soluble programmed cell death ligand 1 in blood impacts overall survival in aggressive diffuse large B-Cell lymphoma: results from a French multicenter clinical trial. Leukemia. 2014;28(12):2367-2375.

106. Muenst S, Hoeller S, Willi N, Dirnhofera S, Tzankov A. Diagnostic and prognostic utility of PD-1 in B cell lymphomas. Dis Markers. 2010;29(1):47-53.

107. Westin JR, Chu F, Zhang M, et al. Safety and activity of PD1 blockade by pidilizumab in combination with rituximab in patients with relapsed follicular lymphoma: a single group, open-label, phase 2 trial. Lancet Oncol. 2014;15(1):69-77.

108. Yang ZZ, Grote DM, Ziesmer SC, Xiu B, Novak AJ, Ansell SM. PD-1 expression defines two distinct T-cell sub-populations in follicular lymphoma that differentially impact patient survival. Blood Cancer J. 2015;5:e281.

109. Chu F, Neelapu SS. Anti-PD-1 antibodies for the treatment of B-cell lymphoma: importance of PD-1+ T-cell subsets. Oncoimmunology. 2014;3(1):e28101.

110. Kantekure K, Yang Y, Raghunath P, et al. Expression patterns of the immunosuppressive proteins PD-1/CD279 and PD-L1/CD274 at different stages of cutaneous T-cell lymphoma/mycosis fungoides. Am J Dermatopathol. 2012;34(1):126-128.

111. Krishnan C, Warnke RA, Arber DA, Natkunam Y. PD-1 expression in T-cell lymphomas and reactive lymphoid entities: potential overlap in staining patterns between lymphoma and viral lymphadenitis. Am J Surg Pathol. 2010;34(2):178-189.

112. Xerri L, Chetaille B, Serriari N, et al. Programmed death 1 is a marker of angioimmunoblastic T-cell lymphoma and B-cell small lymphocytic lymphoma/chronic lymphocytic leukemia. Hum Pathol. 2008;39(7):1050-1058.

113. Blade J, Cibeira MT, Fernandez de Larrea C, Rosinol L. Multiple myeloma. Ann Oncol. 2010;21(Suppl 7):vii313-vii319.

114. Atanackovic D, Luetkens T, Kroger N. Coinhibitory molecule PD-1 as a potential target for the immunotherapy of multiple myeloma. Leukemia. 2014;28(5):993-1000.

115. Castella B, Foglietta M, Sciancalepore P, et al. Anergic bone marrow Vgamma9Vdelta2 T cells as early and long-lasting markers of PD-1targetable microenvironment-induced immune suppression in human myeloma. Oncoimmunology. 2015;4(11):e1047580.

116. Hallett WH, Jing W, Drobyski WR, Johnson BD. Immunosuppressive effects of multiple myeloma are overcome by PD-L1 blockade. Biol Blood Marrow Transplant. 2011;17(8):1133-1145.

117. Liu J, Hamrouni A, Wolowiec D, et al. Plasma cells from multiple myeloma patients express B7-H1 (PD-L1) and increase expression after stimulation with IFN-\{gamma $\}$ and TLR ligands via a MyD88-, TRAF6-, and MEK-dependent pathway. Blood. 2007;110(1):296-304.
118. Yousef S, Marvin J, Steinbach M, et al. Immunomodulatory molecule PD-L1 is expressed on malignant plasma cells and myelomapropagating pre-plasma cells in the bone marrow of multiple myeloma patients. Blood Cancer J. 2015;5:e285.

119. Sponaas AM, Moharrami NN, Feyzi E, et al. PDL1 expression on plasma and dendritic cells in myeloma bone marrow suggests benefit of targeted anti PD1-PDL1 therapy. PLoS One. 2015;10(10): e0139867.

120. Tamura H, Ishibashi M, Yamashita T, et al. Marrow stromal cells induce B7-H1 expression on myeloma cells, generating aggressive characteristics in multiple myeloma. Leukemia. 2013;27(2):464-472.

121. Rosenblatt J, Glotzbecker B, Mills H, et al. PD-1 blockade by CT-011, anti-PD-1 antibody, enhances ex vivo T-cell responses to autologous dendritic cell/myeloma fusion vaccine. J Immunother. 2011;34(5): 409-418.

122. Benson DM Jr, Bakan CE, Mishra A, et al. The PD-1/PD-L1 axis modulates the natural killer cell versus multiple myeloma effect: a therapeutic target for CT-011, a novel monoclonal anti-PD-1 antibody. Blood. 2010;116(13):2286-2294.

123. Wang L, Wang H, Chen H, et al. Serum levels of soluble programmed death ligand 1 predict treatment response and progression free survival in multiple myeloma. Oncotarget. 2015;6(38):41228-41236.

124. Gorgun G, Samur MK, Cowens KB, et al. Lenalidomide enhances immune checkpoint blockade-induced immune response in multiple myeloma. Clin Cancer Res. 2015;21(20):4607-4618.

125. Jing W, Gershan JA, Weber J, et al. Combined immune checkpoint protein blockade and low dose whole body irradiation as immunotherapy for myeloma. J Immunother Cancer. 2015;3(1):2.

126. Kearl TJ, Jing W, Gershan JA, Johnson BD. Programmed death receptor-1/programmed death receptor ligand-1 blockade after transient lymphodepletion to treat myeloma. J Immunol. 2013;190(11): 5620-5628.

127. Ansell S, Armand P, Timmerman JM, et al. Nivolumab in patients (Pts) with relapsed or refractory classical Hodgkin lymphoma (R/R cHL): clinical outcomes from extended follow-up of a phase 1 study (CA209-039). Blood. 2015;126(23):583-583.

128. Armand P, Shipp MA, Ribrag V, et al. Pembrolizumab in patients with classical Hodgkin lymphoma after brentuximab vedotin failure: long-term efficacy from the phase $1 \mathrm{~b}$ keynote-013 study. Blood. 2016; 128(22):1108-1108

129. Moskowitz CH, Zinzani PL, Fanale MA, et al. Pembrolizumab in relapsed/refractory classical Hodgkin lymphoma: primary end point analysis of the phase 2 keynote-087 study. Blood. 2016;128(22): 1107-1107.

130. Ding W, Le-Rademacher J, Call TG, et al. PD-1 blockade with pembrolizumab in relapsed CLL including Richter's transformation: an updated report from a phase 2 trial (MC1485). Blood. 2016; 128(22):4392-4392.

131. Jain N, Basu S, Thompson PA, et al. Nivolumab combined with ibrutinib for CLL and Richter transformation: a phase II trial. Blood. 2016;128(22):59-59.

132. Zinzani PL, Ribrag V, Moskowitz CH, et al. Phase 1b Study of Pembrolizumab in patients with relapsed/refractory primary mediastinal large B-cell lymphoma: results from the ongoing keynote013tTrial. Blood. 2016;128(22):619-619.

133. Badros AZ, Hyjek E, Ma N, et al. Pembrolizumab in combination with pomalidomide and dexamethasone for Relapsed/Refractory Multiple Myeloma (RRMM). Blood. 2016;128(22):490-490.

134. San Miguel J, Mateos M-V, Shah JJ, et al. Pembrolizumab in combination with lenalidomide and low-dose dexamethasone for Relapsed/ Refractory Multiple Myeloma (RRMM): keynote-023. Blood. 2015; 126(23):505-505. 
OncoTargets and Therapy

\section{Publish your work in this journal}

OncoTargets and Therapy is an international, peer-reviewed, open access journal focusing on the pathological basis of all cancers, potential targets for therapy and treatment protocols employed to improve the management of cancer patients. The journal also focuses on the impact of management programs and new therapeutic agents and protocols on

patient perspectives such as quality of life, adherence and satisfaction The manuscript management system is completely online and includes a very quick and fair peer-review system, which is all easy to use. Visit http://www.dovepress.com/testimonials.php to read real quotes from published authors.

Submit your manuscript here: http://www.dovepress.com/oncotargets-and-therapy-journal 